Original Article

\title{
Wooden sticks for plaque streaking and microbiological inoculation might be more cost- effective, but is its large scale use feasible? Quality control methods and proof of concept
}

\author{
Métodos de controle de qualidade e prova de conceito para a utilização de palitos de \\ madeira em microbiologia podem ser mais econômicas, mas seu uso em larga escala é \\ viável? Método de controle de qualidade e prova de conceito
}

\author{
D. M. Castro e Silva ${ }^{\mathrm{a} *}$ (D) and N. S. Adiwardana ${ }^{\mathrm{b}}$ (D) \\ anstituto Adolfo Lutz - IAL, São Paulo, SP, Brasil \\ 'Instituto de Infectologia Emilio Ribas, São Paulo, SP, Brasil
}

\begin{abstract}
The loop is a material classically used in the laboratory for the purpose of plate streaking and handling biological materials. However, metal loops techniques might be time consuming, considering the amount of time spent to guarantee its cooling process through each inoculation. Furthermore, plastic loops may also represent environmental issues during its production and discard process and can also represent higher costs for the laboratory. Thus, in situations of limited resources, even the simplest materials can be restricted due to logistical and budgetary issues, especially in developing countries. Inspired by demands like these, facing an occasional shortage of supply of laboratory plastic handles, we hereby present a quality control for sterilization methods and cost-effectiveness studies towards the use of wooden sticks in a Latin American country and we discuss the possibility of the large-scale use of this technique.
\end{abstract}

Keywords: microbiology; bacteriology; plaque inoculation; wood; waste management.

\begin{abstract}
Resumo
A alça calibrada é um material usado classicamente em laboratório para fins de inoculação em placas e manuseio de materiais biológicos. No entanto, as técnicas de alças metálicas podem consumir muito tempo, considerando a quantidade de tempo gasto para garantir seu processo de resfriamento a cada inoculação. Além disso, alças de plástico também podem representar questões ambientais durante o processo de produção e descarte e também podem representar custos mais altos para o laboratório. Assim, em situações de recursos limitados, até os materiais mais simples podem ser restringidos devido a questões logísticas e orçamentárias, especialmente nos países em desenvolvimento. Inspirados por demandas como essas, diante de uma escassez ocasional de suprimentos de alças de plástico de laboratório, apresentamos um controle de qualidade para métodos de esterilização e estudos de custo-efetividade para o uso de varas de madeira em um país latino-americano e discutimos a possibilidade de grande uso em escala dessa técnica.
\end{abstract}

Palavras-chave: microbiologia; bacteriologia; inoculação em placa; madeira; gerenciamento de resíduos.

\section{Introduction}

The loop is a material classically used in the laboratory for the purpose of plate streaking and handling biological materials. Ranging from metallic wands to the most modern plastic handles, this item is an intrinsic part of the routine of microbiology laboratories. However, metal loops techniques might be time consuming, considering the amount of time spent to guarantee its cooling process through each inoculation. Furthermore, plastic loops may also represent environmental issues during its production and discard process and can also represent higher costs for the laboratory. Thus, in situations of limited resources, even the simplest materials can be restricted due to logistical and budgetary issues, especially in developing countries.

Therefore, this situation reveals a need for innovative products that make laboratory practices simpler in a way to facilitate access to bioresearch, without necessarily demanding technologically elaborated or more complex processes. On the contrary, new products are being developed through the analysis of old instruments whose function have been redesigned to address needs that are now neglected in countries with less financial possibilities. We have as experience the researchers who turned an egg beater (Wong et al., 2008) and a millenary

*e-mail: dulmatos.ial@gmail.com

Received: June 17, 2020 - Accepted: November 25, 2020

This is an Open Access article distributed under the terms of the Creative Commons Attribution License, which permits unrestricted use, distribution, and reproduction in any medium, provided the original work is properly cited. 
toy (Bhamla et al., 2017) into highly efficient, but also low cost laboratory centrifuges, transforming everyday materials into equipment to process biological samples with global health applications. Another fact that draws attention was the creation of a simple, cheap and easyto-transport paper microscope for field research based on a paper-fold origami tradition (Cybulski et al., 2014).

Inspired by works and demands like these, facing an occasional shortage of supply of laboratory handles, we used wooden sticks as substitutes for plastic handles during the process of inoculating and sowing fungi in agar plates, considering it is a resistant material and is classically used in techniques for morphological analysis, mainly in the identification of filamentous fungi. It is known that the use of wooden material can be a reliable source of seeding microbiological samples (Walter, 1968). Through correct sterilization process, it might be used in plaque streaking techniques (Sanders, 2012) and transferring bacterial cultures into glass tubes filled with sterile broth (Walter, 1968). In addition, it is a widely available and relatively affordable item. For this, we developed a process of control and evaluation of the method, which is described below followed by a brief comparative analysis of cost between plastic handles and wooden sticks, considering the reality of public and private laboratory services in a latin american country.

\section{Objective}

To describe the sterilization process, quality control, use and cost comparison of wooden sticks in microbiological laboratory procedures.

\section{Methods}

We sealed 50 units of $30 \mathrm{~cm}$ long wooden sticks with sharp pointed ends in specific plastic packaging for sterilization. Next, we subjected the set to $121^{\circ} \mathrm{C}$ for 15 minutes in a steam autoclave machine (Figure 1 ).

To guarantee the sterility of the material, considering its organic nature, ends of the sticks were split from four different batches of sterilized packages into four sterile tubes with potato agar with chloramphenicol (50mg / $1000 \mathrm{ml}$ of solution) and incubated at $30^{\circ} \mathrm{C}$ for 05 days. If there was no growth of fungi or bacteria in the samples, we considered the sterility control as adequate and released the batch for use in inoculating the fungi under study in

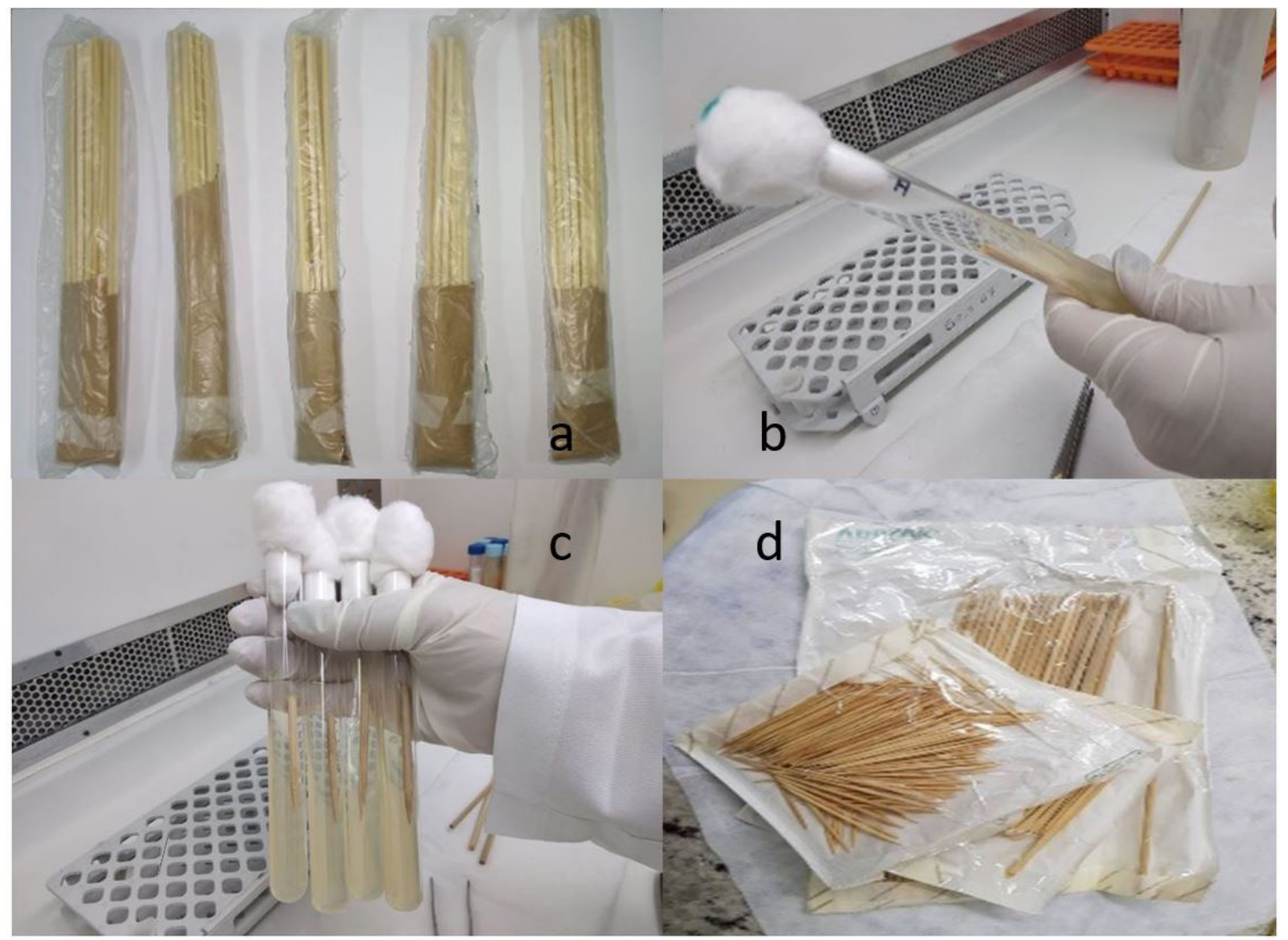

Figure 1. (a) wooden sticks in the steam autoclave sterilization packages; (b) performing the sterilization quality control process; (c) result of the quality control of the process of sterilization of the sticks in potato agar, after incubation for 05 days at $30{ }^{\circ} \mathrm{C}$; (d) toothpicks of other sizes (10 and $20 \mathrm{~cm}$ ) submitted to the same process. 
Table 1. Price list of wooden sticks and plastic loops in public and private institutions.

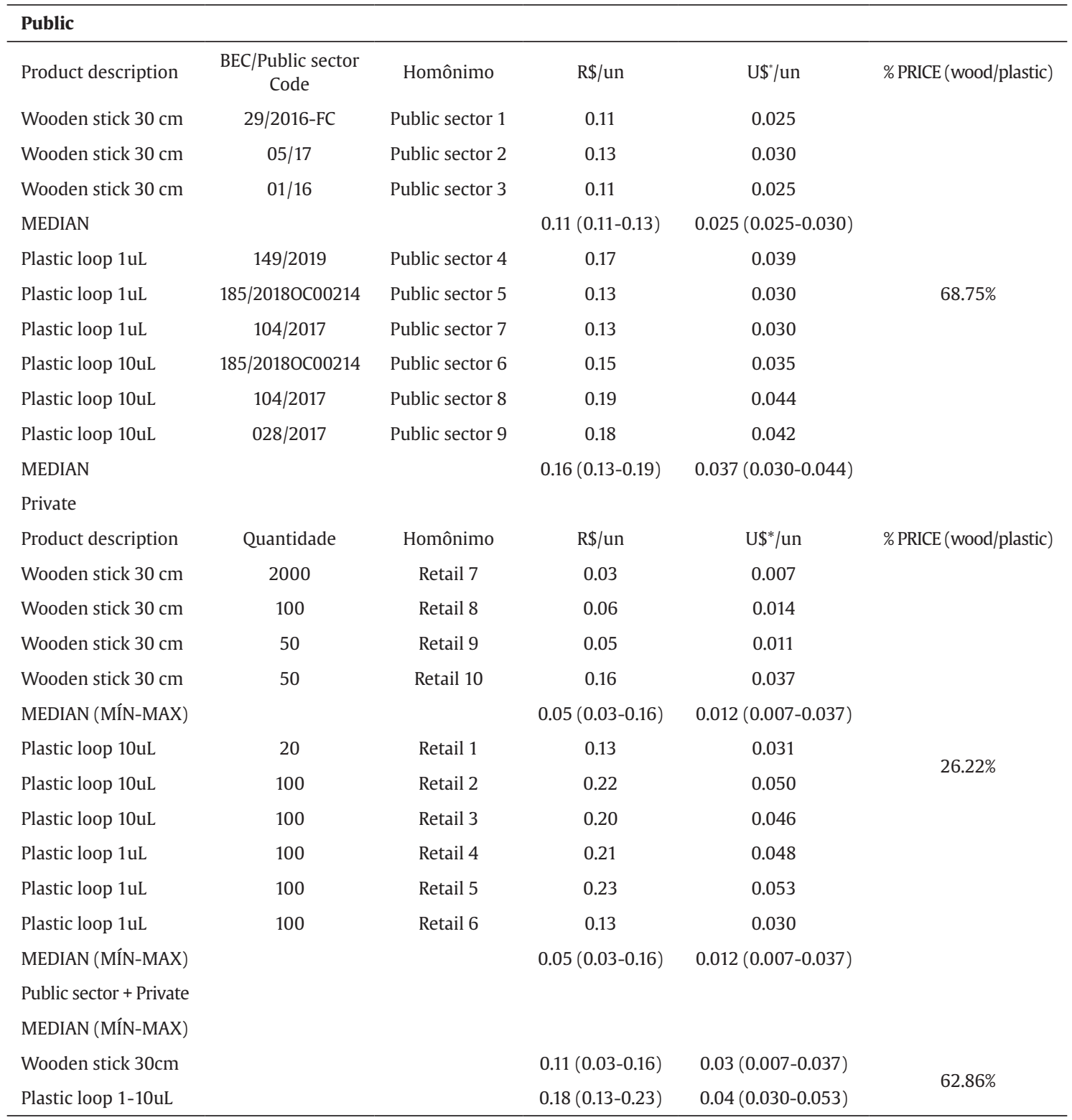

R\$: reais; U\$: US Dollars; *1U\$=R\$4.32 - Exchange rate of February 11th, 2020 - IBOVESPA -São Paulo Stock Exchange Index; un = unit.

the laboratory. We used this technique for six months for inoculation of fungi in culture plates and quantified the success rates (successful inoculation, corresponding to isolation without contamination of the isolated strain) and failure (unsuccessful inoculation, corresponding to absence of growth of the isolated colony or presence of contamination with another unexpected strain).

For estimating the material costs, prices were researched for the public and private sectors, considering the potential price differences negotiated between the two realities. In the public sector, we accessed the electronic trading systems of the State of São Paulo (Brasil, 2019), where prices from years of 2016 to 2019 were investigated. For the private sector, searches were conducted on the electronic web network, using the Google ${ }^{\circledR}$ search engine, at retail sites where offers had current values for products in stock, in order to reflect updated prices. Material prices were cataloged and a median calculation was performed (Table 1).

\section{Results}

During the period of use of the wooden sticks, no contamination was reported in the control tests batch. A total of 66 strains of fungi were isolated and identified using the method, with a success rate during of inoculation of $98.4 \%(65 / 66)$ and a failure rate of $1.6 \%(1 / 66)$, due to the absence of the colony growth in an isolated sample. 
The median price of wooden toothpicks in the public sector was U\$ 0.025 (0.025-0.030), against U\$ 0.037 (0.0300.044 ) for plastic handles, representing a price difference of approximately $68.75 \%$. In retail stores, the medians were U\$ 0.012 (0.007-0.037) and U\$ 0.047 (0.030-0.053) for wood sticks and plastic handles respectively, with a price difference of approximately $26.72 \%$.

\section{Discussion}

Plaque streaking may be executed with several materials. Metal loops may be used multiple times, but need to be constantly flamed with a Bunsen's burner, generating potential aerosolization and cross-contamination of plaques and laboratory surfaces with spore forming bacteria. Plastic loops are usually used with Biosafety Level 2 (BSL-2) strains inside biosafety cabinets, but generates considerable amount of disposable material and may represent higher laboratory expenditure. In contrast, sterilized wooden sticks and flat toothpicks have traditionally been used as an alternative to plastic material for streaking plaques, being specially useful when dealing with soil and environmental specimens, including sporulated bacteria (Sanders, 2012).

Wood is a material widely available in any market on most developing countries. As a commodity, its sustainable production and reutilization through old discarded pieces might contribute to a more ecologically acceptable cycle of production. In addition, its handling involves less chemical processes than the manufacturing of plastic items.

Minimizing waste in laboratories has been scarcely described in scientific literature and a survey applied by the International Federation of Clinical Chemistry And Laboratory Medicine (IFCC) demonstrated that the environmental impact of laboratories is barely addressed by most countries (Lopez and Badrick, 2012). While the United Nations Sustainable Development Goals aim for sustainable cities and communities (UNDESA, 2015), including renewable power and material sources and careful assessment of potential consequences before their deployement (UNDESA, 2019), technical steps during laboratorial production comprise quality measures towards precision and desirable results, but seldom identifies ecologically tolerable frames for those targets.

Nonetheless, to develop alternative technologies does not necessarily implies for the need of more sophisticated machines or materials in a laboratory bench. In order to further spread global access to technologies, analytical process is being remodeled towards simpler but no less functional strategies, based on old knowledge rethought for the same purposes.

A centrifuge may require a precisely balanced and electrically powered motor to provide adequate isolation of substances. But low-middle income countries usually present difficult access to high-cost material or reliable and continuous power sources. Therefore, two different authors have developed alternatives with already known materials and information, publishing methods that utilize a kitchen egg beater (Wong et al., 2008) or a toy paper (Bhamla et al., 2017) principle to surpass such difficulties; Others, in order to facilitate learning of biomedical sciences, have transformed a paper folding japanese art, the origami, into a pocket sized microscope that can be easily attached to a smartphone, which is also easily affordable (Cybulski et al., 2014).

Nevertheless, observing old methods and acquiring simpler techniques can become a cost-effective option for public health systems with low financial budgets. The sole act of re-thinking old designs and practices represent an improvement of pedagogic methods through wider access to basic science technologies and granting higher accountability levels that facilitate incentives in education systems, mainly in scientific subjects (Kremer et al., 2013) - which are crucial steps in establishing a solid and sustainable biomedical education system and practice.

In the presented case, we obtained a process with adequate control of sterility and remarkable improvement in the comfort and safety of handling the samples through the wood material, considering that the wood of the wood stick is harder and its tip sharpened, providing greater precision. This represents an old technique that has easy applicability, high scalability, solid proven sterility control and better ecological impact when planned to be sourced from renewable and certified sources. Furthermore, other sticks size may also prove their usefulness and versatility, not only for plaque streaking, but for other purposes such as more precise isolation of samples in small surfaces. After this episode, 10, 20 and $30 \mathrm{~cm}$ toothpicks have been used in several procedures, mainly with filamentous fungi, without complications or problems. To expand its prospects for use, toothpicks are also being used to prepare samples of bacteria and yeast fungi for reading in a proteomic identification system (Matrix Assisted Laser Desorption / Ionization - Time of Flight | MALDI-TOF, Mass Spectrometry), with no change in results compared to methods using traditional plastic handles.

As for waste management, all wooden waste that should be used to manipulate hazardous biological items should be disposed in boxes destined for sharp-cutting materials, according to local biosafety regulations, and incinerated together with other biological materials for laboratory use (Brasil, 2018). This represents a major challenge for the high carbon impact that both plastic and wood burning generates for the environment. Notwithstanding, scientists debate if wood might actually be considered a carbon neutral resource, considering its carbon consumption may be reabsorbed when a new plant is seeded and developed into a new tree and provide reasonable power sources when its production and consumption cycles are adequately regulated by state agencies (Cornwall, 2017), but this could also mean an accelerated pace in greenhouse effect gases emission in the atmosphere in a short term perspective during the first four decades (Marland and Schlamadinger, 1997; Oliver et al., 2014) - an important aspect to consider when analyzing an already advanced global warming state and irreversible melting of the polar caps (Cornwall, 2017). Aspects of forest productivity and efficiency of the use of harvested materials, biodiversity, new bioenergetic and compound alternatives in concomitant development should be taken into account when planning for long term wood use. A mindful debate must be held towards policies that may be capable to transition from non-carbon neutral 
habits to carbon neutral ones in a short and mid-long term aspects (Cornwall, 2017; Marland and Schlamadinger, 1997).

As some authors have tried to describe measurable impact of stewardship of laboratoy material and techniques (Hobson and Badrick, 2013) and low cost of a waste management policy implementation (Lopez and Badrick, 2012), this study demonstrates a potential for not only carbon neutral techniques, but for the use of a well known and reliable material for a more accessible price. In term of cost effectiveness of the material, the relation of prices of wooden sticks to plastic loops in Brazil represented $68.75 \%$ on public institutions and only $26.22 \%$ on private institutions, which could represent global savings of approximately $37.14 \%$ on a final analysis. Therefore, wooden toothpicks might be an interesting option for both public and private funded laboratories, mainly in low-mid income countries, as long as regulatory agencies promote adequate policies for wood certification - from forest management to wood processing and consumption, to avoid predatory devastation of natural reserves.

\section{Conclusion}

According to the results obtained, we can conclude that the use of wooden sticks instead of the plastic inoculation loop for microbiological techniques might represent a more accessible and carbon neutral technique, providing broader access to heterogeneous conditions throughout different laboratories, as its sterilization control is feasible, it presents better ergonomics, its production and waste cycle might be regulated and it also demonstrates potential cost-effective benefit in a Latin American country, being possibly more accessible in other low-mid countries.

\section{References}

BHAMLA, M.S., BENSON, B., CHAI, C., KATSIKIS, G., JOHRI, A. and PRAKASH, M., 2017. Hand-powered ultralow-cost paper centrifuge. Nature Biomedical Engineering, vol. 1, no. 1, pp. 1-7. http://dx.doi.org/10.1038/s41551-016-0009.

BRASIL. Governo do Estado de São Paulo, Bolsa Eletrônica de Compras - BECSP, 2019 [viewed 10 May 2019]. Available from: https://www.bec.sp.gov.br.</ eref>

BRASIL. Agência Nacional de Vigilância Sanitária - ANVISA, 2018 [viewed 17 June 2020]. Resolução da Diretoria Colegiada - RDC
$N^{\circ}$ 222, de 28 de março de 2018. Regulamenta as Boas Práticas de Gerenciamento dos Resíduos de Serviços de Saúde e dá outras providências [online]. Diário Oficial da República Federativa do Brasil, Brasília. Available from: http://portal.anvisa.gov.br/ documents/10181/3427425/RDC_222_2018_.pdf

CORNWALL, W., 2017. Is wood a green source of energy? Scientists are divided.Science, pp.1-15. http://dx.doi.org/10.1126/science.aal0574.

CYBULSKI, J.S., CLEMENTS, J. and PRAKASH, M., 2014. Foldscope: origami-based paper microscope. PLoS One, vol. 9, no. 6, pp. e98781. http://dx.doi.org/10.1371/journal.pone.0098781. PMid:24940755.

HOBSON, P. and BADRICK, T., 2013. The impact on costs and efficiency of reducing the number of collected tubes. Clinical Chemistry and Laboratory Medicine, vol. 51, no. 4, pp. e53-e55. http://dx.doi.org/10.1515/cclm-2012-0447. PMid:23089806.

KREMER, M., BRANNEN, C. and GLENNERSTER, R., 2013. The challenge of education and learning in the developing world. Science, vol. 340, no. 6130, pp. 297-300. http://dx.doi.org/10.1126/science.1235350.

LOPEZ, J. B., BADRICK, T. and AD HOC IFCC PANEL ON THE ENVIRONMENTAL RESPONSIBILITY OF CLINICAL LABORATORIES; APFCB LABORATORY MANAGEMENT COMMITTEE, 2012. Proposals for the mitigation of the environmental impact of clinical laboratories. Clinical Chemistry and Laboratory Medicine, vol. 50, no. 9, pp. 1559-1564. http://dx.doi.org/10.1515/cclm2011-0932. PMid:22962217.

MARLAND, G. and SCHLAMADINGER, B., 1997. Forests for carbon sequestration or fossil fuel substitution? A sensitivity analysis. Biomass and Bioenergy, vol. 13, no. 6, pp. 389-397. http://dx.doi. org/10.1016/S0961-9534(97)00027-5.

OLIVER, C.D., NASSAR, N.T., LIPPKE, B.R. and MCCARTER, J.B., 2014. Carbon, fossil fuel, and biodiversity mitigation with wood and forests. Journal of Sustainable Forestry, vol. 33, no. 3, pp. 248-275. http://dx.doi.org/10.1080/10549811.2013.839386.

SANDERS, E.R., 2012. Aseptic laboratory techniques: plating methods. Journal of Visualized Experiments, no. 63, pp. e3064. PMid:22617405.

UNITED NATIONS DEPARTMENT OF ECONOMICAL AND SOCIAL AFFAIRS - UNDESA, 2015. Transforming our world: the 2030 agenda for sustainable development A/RES/70/1.USA: United Nations Press.

UNITED NATIONSDEPARTMENT OFECONOMICALAND SOCIALAFFAIRS - UNDESA, 2019. Global Sustainable Development Report 2019 The Future is Now. Science for achieving. USA: UNDESA, vol. 102.

WALTER, W.G., 1968. The use of wooden applicator sticks. The American Biology Teacher, vol. 30, no. 6, pp. 473-475. http:// dx.doi.org/10.2307/4442150.

WONG, A.P., GUPTA, M., SHEVKOPLYAS, S.S. and WHITESIDES, G.M., 2008. Egg beater as centrifuge: isolating human blood plasma from whole blood in resource-poor settings. Lab on a Chip, vol. 8, no. 12, pp. 2032-2037.http://dx.doi.org/10.1039/b809830c. PMid:19023465. 